\title{
The Use of Management Information System to Help Decision Making in Digital Firms
}

\author{
Atyeh Mohammed Alzhrani \\ MBA-Taif University \\ Saudi Arabia , 2020 \\ E-mail: atzhrani@gmail.com
}

\begin{abstract}
Management Information System (MIS) gives information for the managerial activities digital firms. This paper focuses on understanding the vital role of using management information system (MIS) in decision making in digital firms. It talks about considering the concept of MIS, the necessary use of MIS and the impact of the smart usage of MIS in decision making in digital firms. The study discusses MIS importance on decision making depending on a descriptive analytical method, in which the idea is discussed and described in an accurate methodology with analysis, through presenting and discussing previous studies, then relying on the comparative approach to know the role of using MIS in Digital organizations. The study revealed the effect of using MIS in decision making as a smart usage of MIS tool helps achieving a great success and minimizing the investigation of time in addition to increasing the profit of organizations. Also, it shows how decisions are made in digital firms using MIS and the challenges that the organizations facing in this process and a few recommendations to curb these challenges.
\end{abstract}

\section{Keywords: The Use, Management Information Systems (MIS), Decision Making, Digital Firms.}

\section{Introduction}

A development in Management Information System occurred in the past 30 years and it has become essential tool for business nowadays. It is a handy tool that concerning with the gathering, storing and transferring information across all levels in an organization. Thus, MIS is considered as a central storage of all the business information that can help managers to take the right decisions effectively and in suitable amount of time.

In digital firms, a faster access to the necessary information that assists in decision making is a very important thing. As decision making concerns with choosing a certain action in several activities in an organization. The effective management of the organization is measured by the quality of decisions that informs its operation. Thus, it becomes very important to know how to best use MIS in decision making and what the challenges should be faced to achieve success to organization.

\section{Questions of the study}

- What is the meaning of Management Information System (MIS)?

- What are the main elements and functions of Management Information System (MIS)?

- What is the relationship between MIS and decision making in an organization?

- How decisions are made in digital firms using MIS?

- What are the challenges that the organizations facing in front of decision making?

3. Purpose of the study

- Know the concept of MIS.

- Show the development approach of Management Information System

- Determine the relationship of MIS and decision making.

- Determine the Criteria of Management Information System.

- Know the requirements of a successful Management Information System.

- Determine the challenges of accessing MIS in decision making.

4. Importance of the study

- Know the importance of using MIS to help managers in decision making.

- Show models of Management Information System.

- Comparing between decision making before and after MIS.

- Give answers on how to overcome the challenges in use MIS in decision making. 


\section{Methodology}

The study discusses MIS importance on decision making depending on a descriptive analytical method, in which the idea is discussed and described in an accurate methodology with analysis, through presenting and discussing previous studies, then relying on the comparative approach to know the role of using MIS in Digital organizations.

\section{Recent Studies}

- According to (Alabi, 1997) there are four types of search for information. The importance of searching is providing alternative information so that comparing process can be done. And so there will be alternative choices of required action to reach the final result. (Satyanarayana et al., 2009)

- Undirected viewing: The viewer may not have specific purpose in mind as it is an exposure to information in general.

- Conditioned viewing: Not depends on active search for defined type of information.

- Informal search: The information is for a specific reason. But the effort to obtain it is not structured.

- Formal search: Require a structured plan, procedures or methodology to make a specific information in known issue be safe and secure.

- According to (Ogunsaju, 1990) the process of making decision is depending on presence of alternatives for the relevant information. Ogunsaju pointed out to the importance of using informed evidence in making decision. The effectiveness in making decision process in any organization is based on determining the source of information and people who will transfer this information through the organization.

- Therefore, in digital firms the communication of information must be accurate and up-to-date to cope with uncertainty. Uncertainty happens when the manager has little information relevant to a decision and there is no way to predict the result of the decision.

- The study of (Hussain, 1973) pointed to the important of information in decision making. Sisodia considered the decision making as a completed process that begins with gathering information, evaluation of alternatives and then reaching to a final choice. The manager plays the first role to design and manage the flow of information and the ways of transfer it through the organization. Gathering information is depending on answering important operating and strategic questions.

- According to (Adesina, 1988) the amount of information available to a decision-making group affects the final result of that group. Thus, the manager must be concerned with facilitating the free flow of information inside the organization. The use of effective management information system (MIS) helped to reach the successful decision.

- The study of (Obi, 2003) added a valuable result of using MIS in decision making and pointed to its benefits in controlling the system of any disturbances. Obi also mentioned that MIS is a supporting method to supply information, doing an evaluation to it until complete the decision-making process.

- Fabunmi (2003) also mentioned that using MIS is useful in making decisions to solve a lot of the problems facing educational institutions. Such problems include weak scheduling, lack of requirements or accurate information on students and lack of feasible budget estimates among others.

- On other hand, (FA, 2007) pointed to the need for MIS in decision making as it gives information that is needed for better decision making on the aspects affecting the organization regarding human and material resources.

\section{Discussion}

\section{I Concept of Management Information System (MIS)}

Management Information System may be known as a formal way of making decision by management accurate and timely information relevant to facilitate the decision-making process and helping the organization's managers to design effective plans achieving effective functions (Ranisavljević et al., 2012).

The system gives information on the past, present and projected future and to make sense to events inside and outside the organization. The purpose of MIS is to help in decision making and not to automate the decision-making process itself. Secondly the concentration of MIS should be only on those decisions whose benefit/cost ratio is attractive.

- Data: raw material of facts.

- Management: The direction of an organization who is responsible for putting plans, organizing, coordinating and controlling of its human and material resources to achieve a success to the organization.

- Information:

It is gathering process of facts for providing the knowledge. Information is the common element that holds an organization together.

- System:

A group of procedures, processes, methods, routines or techniques that assembled by some form of regulated calculations to form an organized unit. 


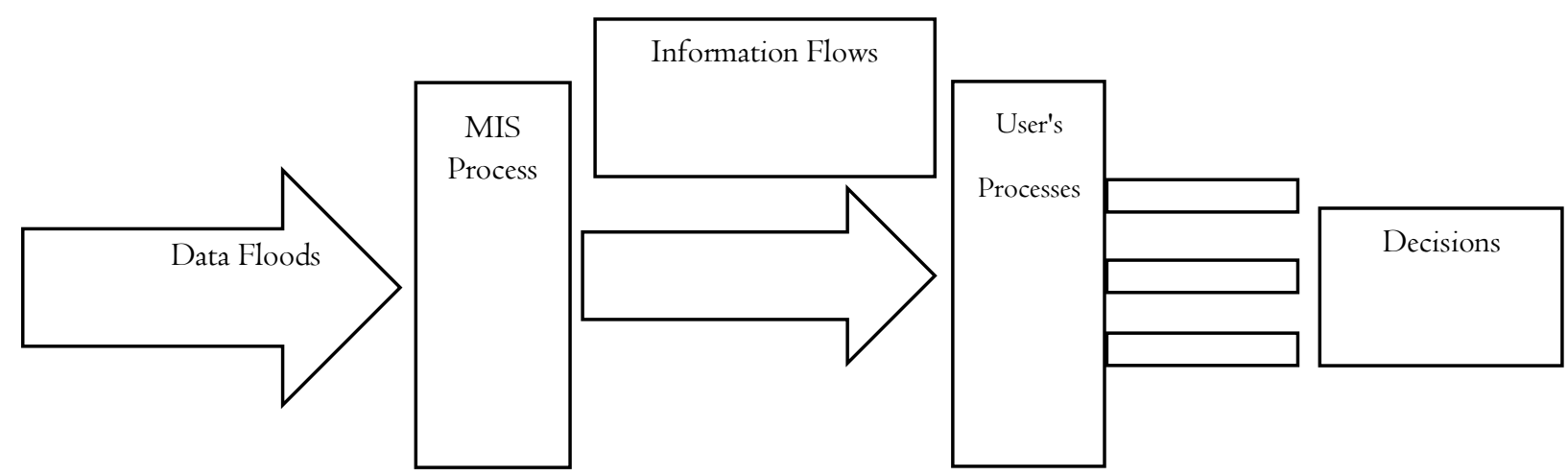

Figure I. MIS and decision-making process

\subsection{Elements of Management Information System}

There are many elements that control MIS in digital firms. Such as:

- Management: The person who uses the information.

- Find Personnel: Determining the activities which requires generating the data of the database of the MIS.

- The Computer Hardware: Helping in storing the data base which is used for generating the required information.

- The Computer Software: Doing processes on the data from the database using the hardware to convert these to information.

- Computer Personnel: The supplier, who able to deal with the computer and maintain the information on the computer.

\section{3 Functions of Management Information System}

The importance of using MIS in digital organizations appears in providing these services to the organizations:

- Effective and efficient coordination between Departments

- Quick and reliable referencing

- Access to relevant data and documents

- Use of less labor

- Improvement in organizational and departmental techniques

- Management of day-to-day activities

- Day-to-day assistance in a Department and closer contact with the rest of the world.

- Gives a valuable time-saving benefit to the workforce.

\section{4 Criteria of Access MIS in Decision making}

According to Haynes and Massie, a decision is a type of action which is consciously chosen for achieving a desired result. On the other hand, Trewatha and Newport define the decision making as a choosing process between two of more possible alternatives to make a solution in certain problem.

The organization's manager should have the full knowledge of MIS which is considered to classify them from the point of timing and detail.

- Frequency of Decision Making:

The frequently rate for decisions required to be made.

- Response Time Required:

Time is a main important factor in making decisions, as some of them are urgent and some managers require them immediately.

- Degree of Processing Required:

In digital firms there are super processing power of computers to generate information. The information should be in absolute detail.

- Amount of Information Required:

According to an economic law (80/20 law) developed by the Italian economist Wilfred Pareto, 20\% of the information generated should meet the $80 \%$ of the need of information of a manager for a particular decision making. 


\section{5 Models of Management Information System}

There are many models suggested by many experts, two of which are briefly discussed below:

\subsection{The three Stage of Bowman's Model}

The model consists of three stages to achieve a successful MIS implementation:

Level I:

Depend on the long-range corporate planning process, called Strategic Planning. The strategic Management Information System [MIS] Planning is helpful in deciding on what information the system should be able to provide and the manner of it. It begins with the needs of the Top Level of Management, which are identified first.

Level 2:

This step comes after the first one in level I. It assesses the total requirement of information need of the organization, even for strategic, tactical, and operational decision making, using the top-down approach.

Level 3:

Build up the management information system by defining the suitable resources. Then operate the new system

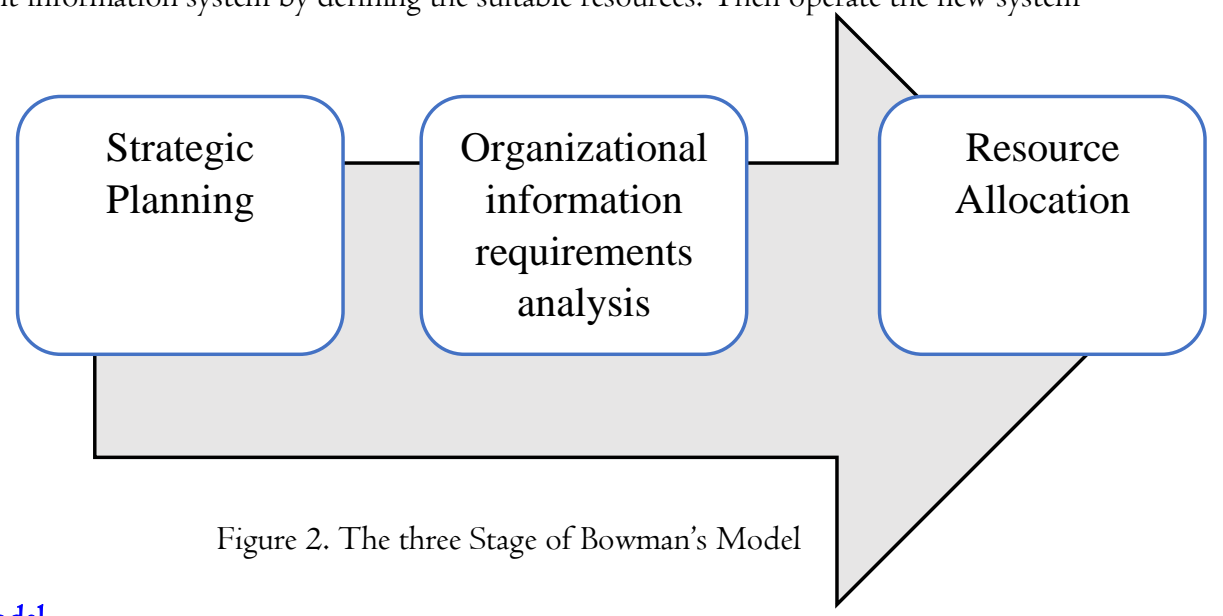

\subsection{Earl's 3-Level Model}

The three levels have been defined as:

- Information System Strategy: ISS

- Information Technology Strategy: ITS

- Information Management Strategy: IMS

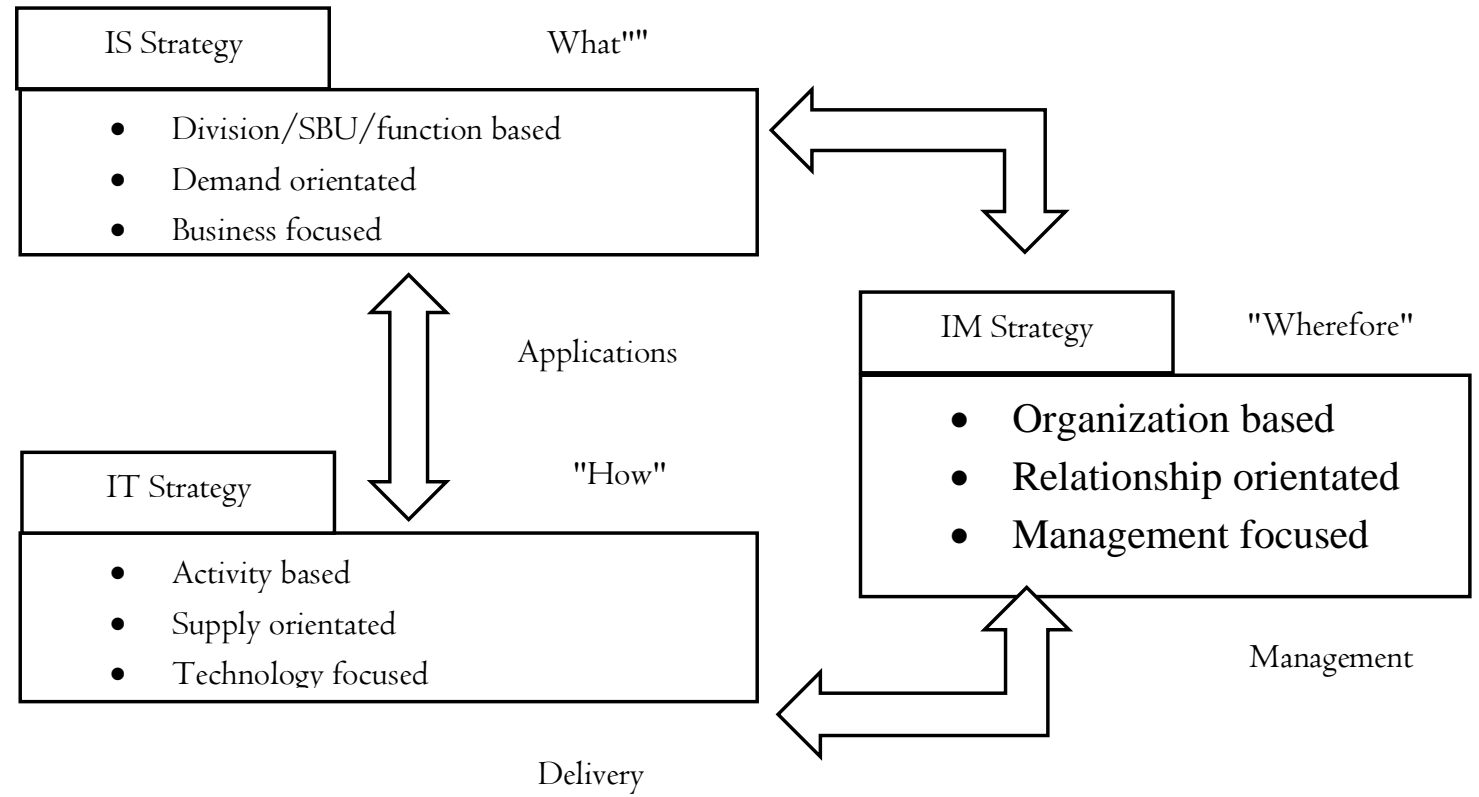

Figure 3. The three levels of Earl's 3-Level Model 
- Information System Strategy:

Define the overall business strategy which has different levels, and so defines the total information requirement of the organization at different levels.

- Information Technology Strategy:

Evaluation and determination of the available computer technology and its continuous developments would help in catering the requirement known at ISS level. In addition to know the networking and other communication facilities required.

- Information Management Strategy:

The final level involves the total strategy that is concerned with planning in detail how the organization will manage its both information system and technology, to meet organizational requirement of information. It defines the rules and regulations, authority, and funding of the total system development. It is a mixture of both the top-down and bottom-up approach.

However, the choosing the first or second model there is a must of commitment for the top level of management.

\section{Results of the study}

By considering the recent studies, it clearly appears the differences between lack of MIS in decision making and the impact of using it in modern age. From total lack of suitable touch, then using the complicated computers that gives errors in information, then founding a more static system which was highly insensitive to environmental changes and finally to have more operative system (MIS) helping in decision making.

\section{- Requirements of a Successful Management Information System:}

In order to overcome some challenges that facing applying MIS in decision making process, these requirements should be considered (Dyer WG, I990).

- Data should be timely, relevant and accurate according to the requirement of the organization's management.

- Flexibility to changes in operation and environment is an important factor of the data gathered.

- Reliability to ensure that decision depend on the information generated by the system do not lead to disasters.

- The system should be simple to operate and maintain by users, with minimum skill required.

- Minimum cost is more effective for build up the system. Considering the benefits, as it should be more than the resources required.

- The system must depend on needs in all the levels of management.

- Ensure of security of the system to prevent unauthorized copying of vital information by anyone.

- Recovery after any disaster should be easily.

- Authorization of the system to prevent access to anyone and thus a vital destroy to database may be happened.

-The Future of Management Information System:

Although there are some individuals that don't cope with MIS, there are companies considering it as very effective especially in making decision as it helps achieving a great success and minimizing the investigation of time in addition to increasing the profit of organizations (FA, 2007).

Due to the rapid process of science of information technology, there is a major increase in interest in the concept of this science. However, more studies are required in the field of management of information system to provide organizations with modern methods and solutions.

\section{Recommendations}

In order to facing the huge amount of information, the management information should be stored in some kind of a system. The management information system should be classified according to the activities of every organization and it should be precise in order to have valuable decision making.

Recording the final results of decision making and know its reasons.

In order to overcome the errors and problems in the process of gathering the information, organize and analyzing it, more effort is required to encourage the researches in that field and to face the changes result from development of the age.

\section{I0. Conclusions}

Management of information system is considered a very smart tool that can help managers in decision making process. However, modern age changes quickly and so some challenges revealed in decision making process that affects the success of organization. Thus, it should be more improvements in the method of gathering information to cope with the continuously changes. Moreover, time and precise are very important factors in making decisions, so more studies needed to improve management of information system. 


\section{References}

Adesina, A. (1988). Decision-making in educational administration.

Alabi, A. T. (1997). Management Information System (MIS) and Effective Control in Nigerian Universities: A Case Study of University of Ilorin. In Post-graduate seminar on Productivity, Effectiveness and Efficiency in Education, University of Ilorin.

Dyer WG, D. H. (1990). The Challenges of Management. . New York: Harcourt Brace Jovaniocvich.

FA, A. (2007). Management Information System for Managers. AdoEkiti: Green Line Publishers.

Fabunmi, M. (2003). Management Information Systems in Education. Basic Text in Educational Planning. Ibadan: Department of Educational Management, University of Ibadan, Ibadan.

Hussain, K. M. (1973). Development of information systems for education. Prentice Hall.

Obi, E. (2003). Educational Management: Theory and Practice. JAMOE Nigeria Enterprises.

Ogunsaju, S. (1990). A guide to school effectiveness in Nigeria. Laville Publications.

Ranisavljević, P., Spasić, T., \& Mladenović-Ranisavljević, I. (2012). Management information system and decision making process in enterprise. Economics, Management, Information and Technology EMIT, I, I84-I94.

Satyanarayana, R., Rallabandi, S., Srikanth, R., \& Vuda, S. (2009). Management information system to help managers for providing decision making in an organization. International Journal of Reviews in Computing, I(5), I-6.

\section{Copyrights}

Copyright for this article is retained by the author(s), with first publication rights granted to the journal. This is an open-access article distributed under the terms and conditions of the Creative Commons Attribution license (http://creativecommons.org/licenses/by/4.0/). 